\title{
Detalhamento sobre o triptofano e sua importância no combate aos agentes que levam à depressão: avaliação sobre o produto triptolife
}

\author{
Dr. Fabiano de Abreu Agrela Rodrigues ${ }^{1}$ \\ deabreu.fabiano@gmail.com \\ CPAH- Centro de Pesquisas e Análises Heráclito - Brasil \\ Aveiro, Castelo de Paiva - PORTUGAL
}

\section{RESUMO}

O presente artigo tem por temática o aminoácido triptofano, sua importância para a sobrevivência e a necessidade desta substância para a homeostase em nosso organismo. Mediante a um momento de pandemia onde estão presentes disfunções em neurotransmissores, entre elas os provenientes do triptofano, que são essenciais, também, para evitar doenças e mortes consequentes destas disfunções. O artigo visa detalhar sobre este aminoácido, as suas funções, como é encontrado nos alimentos. Serve também para avaliar o produto Triptolife e suas condições para suprir a necessidade do organismo, conseguindo atravessar a barreira hematoencefálica já que nem todos os alimentos conseguem fazer.

Palavras-chave: aminoácidos; triptofano; sistema nervoso central; depressão

\footnotetext{
${ }^{1} \mathrm{PhD}$, neurocientista, neuropsicólogo, mestre em psicanálise, especialização em propriedades elétricas dos neurônios, pós graduação em antropologia, jornalista, especialização em inteligência artificial e especialista em nutrição clínica.
} 


\title{
Details about tryptophan and its importance in combating agents that lead to depression: Evaluation of the triptolife product
}

\begin{abstract}
This article has as its theme the amino acid tryptophan, its importance for survival and the need for this substance for homeostasis in our organism. Through a pandemic moment where neurotransmitter dysfunctions are present, including those from tryptophan, which are also essential to prevent diseases and deaths resulting from these dysfunctions. The article aims to detail about this amino acid, its functions, as found in food. It also serves to evaluate the Triptolife product and its conditions to supply the body's need, managing to cross the blood-brain barrier since not all foods can do it.
\end{abstract}

Keywords: amino acids; tryptophan; central nervous system; depression

Artículo recibido: 02 enero 2022 Aceptado para publicación: 28 enero 2022 Correspondencia: deabreu.fabiano@gmail.com Conflictos de Interés: Ninguna que declarar 


\section{INTRODUÇÃO}

\subsection{Triptofano}

O triptofano é um aminoácido essencial que serve a vários propósitos importantes, como equilíbrio de nitrogênio em adultos e crescimento em bebês. Também é usado para produzir niacina, que é essencial para a criação do neurotransmissor serotonina.

É um aminoácido essencial, não sendo produzido pelo organismo por seres humanos e outros animais, precisando assim, ser ingerido através de proteínas animais e vegetais. Fundamental para as questões emocionais, evitar doenças e até a morte precoce. (COMAI, 2020)

O triptofano promove o aumento da produção de serotonina no sistema nervoso central (SNC) dessa maneira, regula o humor, apetite, sono; em tratamentos de depressão, ansiedade, estresse e hiperatividade em crianças. (GHEORGHE, 2019) Comercialmente vendido em capsulas, como composto em fármacos ou na composição de alguns leites em pó para uso infantil. (SONGTACHALERT, 2016)

É um substrato para a produção de diversas moléculas neuroativas com atividades biológicas, como a serotonina (5-HT), a melatonina, a 3-hidroxiquinurenina (3-HK), o ácido quinolínico (AQ), ácido quinurênico (QUINA), dentre outros. (KALUZNA, 2019) Contém como outros aminoácidos, um grupo animo (básico) e um grupo carboxilo (ácido) e em sua cadeia lateral um indol, sendo assim um aminoácido aromático e apolar. Seu $\mathrm{pH}$ fisiológico, é classificado como zwitterion o grupo amino $\left(\mathrm{pK}_{\mathrm{a}}=9.39\right)$ sendo o protonado $\left(-\mathrm{NH}_{3}{ }^{+}\right)$e o grupo carboxila $\left(\mathrm{pK}_{\mathrm{a}}=2.38\right)$ fica deprotonado $\left(-\mathrm{COO}^{-}\right)$, podendo ser absorvido através da luz ultravioleta. (KALUZNA, 2019)

O 5-hidroxitriptofano (5-HTP) é um tipo de aminoácido, este produzido pelo organismo a partir do aminoácido essencial L-triptofano. Em seguida da conversão do L-triptofano em 5-HTP, uma enzima chamada L-aminoácido aromático descarboxilase transforma o 5-HTP em serotonina. (KALUZNA, 2019)

A síntese de 5-HT a partir do triptofano envolve diversas etapas. Inicialmente o L-TRI é hidroxilado e convertido em 5-hidroxitriptofano (5-HTP) pela ação da triptofano hidroxilase, que utiliza como cofatores o oxigênio e a tetrahidrobiopterina (KESZTHELYI et al., 2009; STAVRUM et al., 2013; PALEGO et al., 2016). Em seguida, o 5-HTP é descarboxilado, a partir da enzima descarboxilase dos L-aminoácidos aromáticos, que utiliza como cofatores piridoxal 5-fosfato, 28 magnésio e vitamina B3, 
dando origem a 5-HT (KESZTHELYI et al., 2009; STAVRUM et al., 2013; PALEGO et al., 2016).

Existem dois tipos de triptofano: L-triptofano e D-triptofano. A única diferença entre os dois tipos é a orientação da molécula.

Figura 1 - Estrutura química do triptofano e 5-Hidroxi-triptofano

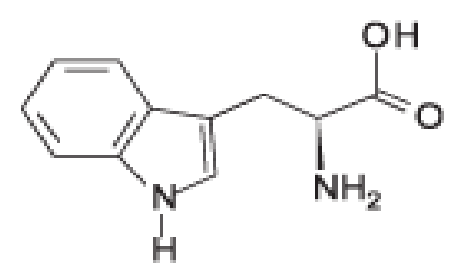

Triptofano

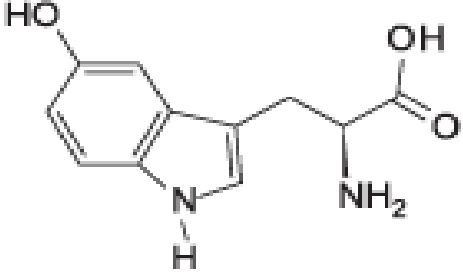

5-Hidroxi-triptofano

Cerca de $90 \%$ do Triptofano ingerido localiza-se ligado à albumina do plasma, e 10\% de maneira livre na circulação sanguínea. Em relação aos ácidos graxos não esterificados eles se demonstram fundamentais no equilíbrio entre a proporção de triptofano de maneira livre ou ligado à albumina, visto que competem com tal aminoácido pela ligação com a albumina plasmática, levando ao aumento dos níveis de triptofano livre no plasma. (KALUZNA, 2019)

O método de extração mais utilizado é a cromatografia líquida de alta eficiência (CLAE). A extração de 5-HTP pode ser realizada através de acetonitrila ou metanol aquosos ou troca catiônica, sua separação é feita por meio de eletroforese capilar ou CLAE de fase revers, pois o mesmo é facilmente detectado por absorção de luz ultravioleta florescencia ou espectrometria de massas. (MARTINS, 2010)

Pode ser usado para a extração de triptofano e 5-HTP: água e tampão fosfato de potássio $0,1 \mathrm{M}$, acetonitrila a $7 \%$, metanol a $50 \%$ e $\mathrm{HCl} 0,1 \mathrm{~mol} / \mathrm{L}$. Sendo obtidos principalmente através do café e soro de leite. (MARTINS, 2010)

Os cinco aminoácidos competidores pela passagem através da barreira hematoencefálica são: leucina, isoleucina e valina (aminoácidos de cadeia ramificada: ACR), além da tirosina e fenilalanina (aminoácidos aromáticos). Entre os cinco aminoácidos competidores, o que possui a menor concentração plasmática é o triptofano $(50 \mu \mathrm{M})$. É estimado que a razão entre TRP:AN seja de 1:100.

\subsection{Sistema Nervoso Central (SNC)}

Anatomicamente o SNC está localizado no interior do crânio (encéfalo) e no canal 
vertebral (medula espinal) dos vertebrados, assim como o sistema nervoso periférico possuí papel importante no controle do organismo. Através dele que as informações relacionadas aos sentidos: audição, visão, olfato, paladar e tato são transmitidas para os músculos e glândulas. (ALDRICH, 2019)

Sendo dividido em duas regiões: substância cinzenta e a branca. Na cinzenta, existem os corpos celulares dos neurônios e seus dendritos, na substância branca é predominante a presença de axônios que tornam a região mais clara, por isso é chamada de substância branca.

O encéfalo, é a parte do SNC que está alojada no crânio. Sendo formado por bilhões de neurônios sendo dividida em; cérebro, tálamo, hipotálamo, mesencéfalo, cerebelo, ponte e bulbo.

A medula espinal, está localizada no interior da coluna, sendo um cordão cilíndrico possuindo função de transmitir mensagens do encéfalo para outras partes do corpo e o até o encéfalo.

O neurotransmissor serotonina é sintetizado nos neurônios serotoninérgicos do SNC e nas células enterocromafins (células de Kulchitsky) do trato gastrointestinal produzido a partir do aminoácido triptofano, capaz de controlar emoções, influenciar habilidades motoras, processo digestivo e fluxo sanguíneo. (STRASSER, 2016)

A maior parte da serotonina corporal, cerca de $95 \%$, é produzida no trato gastrointestinal pelas células enterocromafins, no intestino, e pelos neurônios serotoninérgicos do sistema nervoso entérico (GERSHON, 2000; GERSHON, 2004; GERSHON; TACK, 2007). No sistema nervoso entérico, a 5-HT é um neurotransmissor excitatório considerado importante por ser responsável por estimular as contrações peristálticas e secretórias pósprandial, além de ativar os nervos sensoriais extrínsecos (GERSHON; TACK, 2007).

Alterações no sistema serotoninérgico podem levar a disfunções do trato gastrointestinal. A síndrome do intestino irritável (SII), uma doença gastrointestinal funcional caracterizada por dor ou desconforto abdominal associados a alterações na característica das evacuações, está sendo tratada com medicamentos antidepressivos da classe de Inibidores Seletivos de Recaptação da Serotonina (CATAPANI, 2004; PASSOS; RAMOS, 2006).

Em indivíduos com depressão é comum os níveis do neurotransmissor estarem baixo, por isso a indicação do triptofano nesta população. Em um organismo sem depressão, os picos 
de elevação da serotonina ocorrem em atividades como por exemplo sexo ou comer algo que o indivíduo gosta muito, levando a sensação de felicidade de bem-estar. (SONGTACHALERT, 2016)

Figura 2 - Estrutura química da serotonina

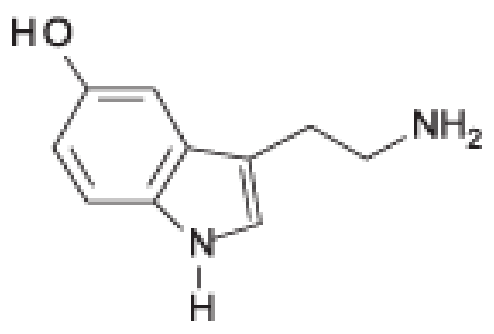

\section{Serotonina}

\subsection{Patologias relacionadas ao triptofano}

A depressão é uma patologia comum e séria que afeta negativamente a maneira de como o indivíduo sente, pensa ou age, podendo ser tratada através de medicamentos. (LEE, 2019)

Os sintomas são sentimento de tristeza e/ou perda de interesse nas atividades que o indivíduo sentia prazer em realizar antes, diminuição da capacidade de se manter em atividades normais do dia a dia como trabalho e em casa. (LEE, 2019)

Devido ao fato de o triptofano influenciar no SNC e atuar no controle das emoções, concluindo assim que o consumo de triptofano gera melhora dos sintomas depressivos e até redução da ansiedade. (LEE, 2019)

A insônia pode estar relacionada à casos de maus hábitos de sono, depressão, ansiedade, sedentarismo, doença crônica e alguns fármacos. Alguns dos sintomas são dificuldade para dormir ou dormir e não se sentir descansado. O triptofano influencia no hormônio melatonina que irá atuar na melhora do sono.

O triptofano também é eficaz de atuar no tratamento da ansiedade alimentar com excesso de consumo de alimentos. Podendo atuar controlando o humor e sendo capaz de suprimir desejos de alimentos e álcool.

Vivemos um momento em que a mídia social, internet em excesso e jogos estão causando disfunções em neurotransmissores, entre eles a serotonina como consequência da rotina e liberação em excesso e contínuo de outros neurotransmissores como a dopamina que descontrolam e prejudicam a homeostase. Como precursor da serotonina, o triptofano 
torna-se uma necessidade para muitos que sofrem do mal da internet.

\subsection{Processo de absorção do Triptofano}

Ao ser ingerido o aminoácido pode permanecer na corrente sanguínea ou ser levado ao sistema nervoso central (SNC), onde será convertido em serotonina.

Podendo seguir por vias metabólicas: via 5-HT (1-2\%), via quinurenina (95\%), degradação bacteriana (4-6\%) e a síntese de proteínas, não tendo um consenso sobre a porcentagem (variando entre 30\% a 90\%) de triptofano, pois a necessidade do organismo da síntese induz para tal caminho. (KESZTHELYI et al., 2009).

Porém nem todo aminoácido é capaz de chegar ao cérebro devido a barreira hematoencefálica (BHE). (MALKIEWICZ, 2019)

Tal barreira é formada por uma estrutura que permite uma permeabilidade seletiva atuando como protetor do SNC, de substâncias tóxicas que tentando adentrar. Dessa forma, o triptofano precisa ultrapassar tal barreira, sendo necessário um transportador de aminoácidos, pois existe uma competição entre os outros aminoácidos do alimento que foi ingerido, para que ocorra sua absorção. (MALKIEWICZ, 2019)

Figura 3 - Barreira Hematoencefálica

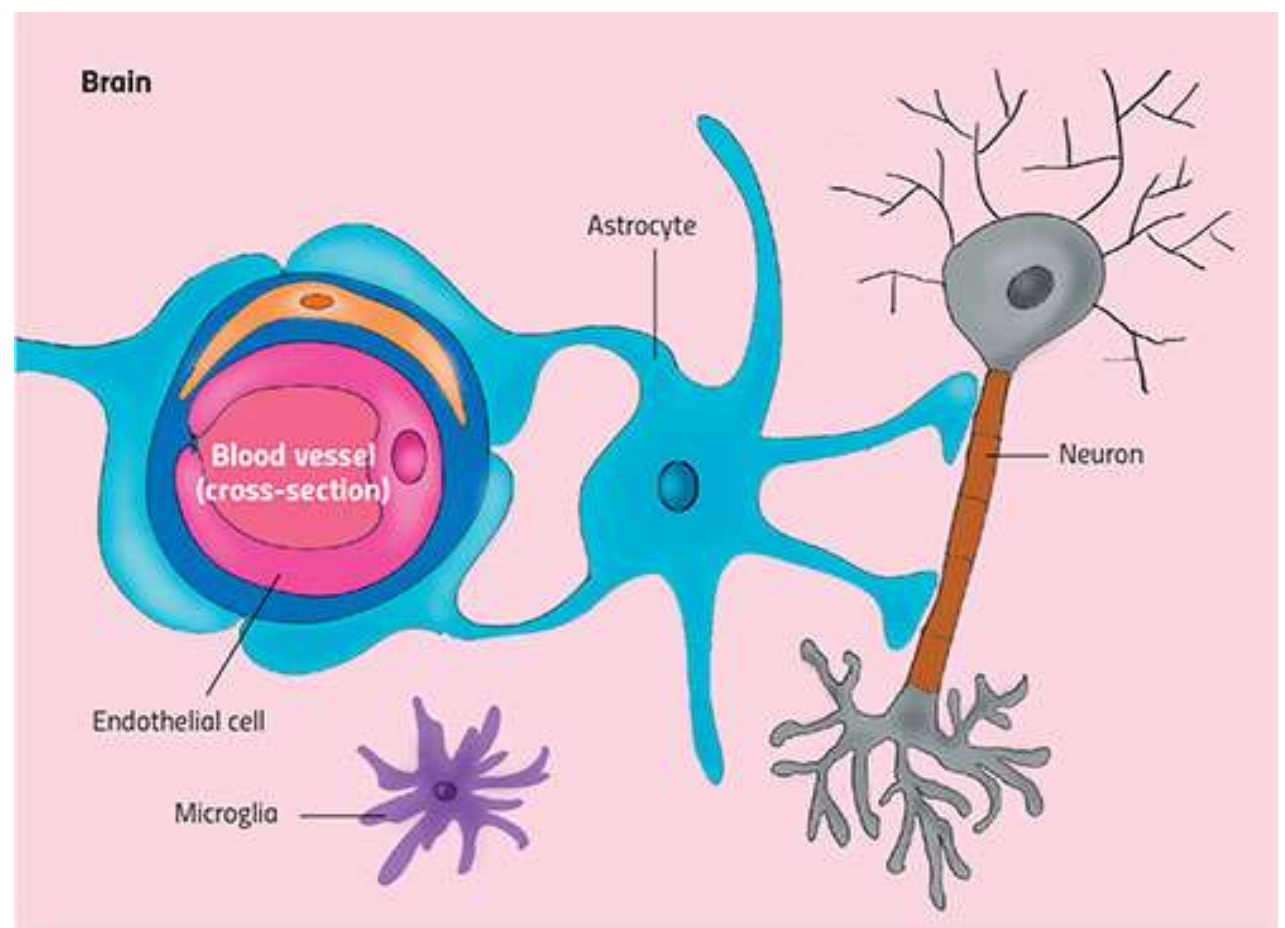

Legenda: Brain: Cerebro, Blood Vessel (cross-section): Vaso sanguíneo (seção transversal), Astrocyte: Astrócito, Endothelian cell: Célula endotelial, Microglia: Microglia, Neuron: Neuroneo 


\subsection{Alimentos que contém Triptofano}

Em alguns alimentos naturais é possível encontrar o triptofano, como por exemplo: bananas, semente de abóbora, soja, grão-de-bico, tâmaras secas, amendoins, leite, carne, peixe, peru e alimentos ricos em proteínas. No entanto por exemplo, a banana possuí o TRP mais não é absorvido.

Associado ao triptofano, a vitamina B3 (niacina ou niacinamida) e o magnésio auxiliam na produção de serotonina. (STRASSER, 2016)

Embora o triptofano aumente a serotonina, o consumo de tais alimentos não irão demostrar efeitos significativos no SNC isso porque, o aminoácido não é o único nutriente presente no alimento e quando ingeridos irá ocorrer tal competição na Barreira Hematoencefálica, impedindo total absorção de triptofano. (STRASSER, 2016)

\subsection{Composição do fármaco Triptolife}

O Triptolife é um suplemento de triptofano da empresa Life Natural, utilizado para que o corpo consiga realizar a absorção adequada do aminoácido, que não é presente em nosso organismo e que não é totalmente absorvido quando ingerimos alimentos.

Sendo contraindicado em casos de uso de medicamentos antidepressivos ou calmantes, pois a combinação do medicamento com o suplemento pode causar problemas cardíacos, ansiedade, tremores e sonolência excessiva. Além disso, mulheres grávidas ou que amamentam também devem evitar o uso desse suplemento.

Para obter um bom resultado com o suplemento é recomendado pelo fabricante a ingestão de 4 cápsulas por dia, preferencialmente antes das refeições, sendo recomendado uso por no mínimo 3 meses para um resultado surpreendente. Seu uso em excesso pode levar a efeitos colaterais como azia, dor de estômago, enjoos, vômitos, gases, diarreia, perda de apetite, tonturas, dores de cabeça, boca seca, fraqueza muscular e sonolência excessiva.

\section{A seguir a bula do suplemento com todas as informações passadas pelo fabricante:}

- Frasco com 60 cápsulas de 215 mg cada

- Conservar ao abrigo da luz, calor e umidade. Após aberto conservar bem fechado e em local seco.

- Não exceder a recomendação diária de consumo indicada na embalagem. Manter fora do alcance de crianças 
Ingredientes: L-TRIPTOFANO

Composição da cápsula: gelatina Não contém Glúten

Recomendação de uso: ingerir 01 cápsulas ao dia.

Produto indicado para o grupo populacional maior ou igual a 19 anos.

Este produto não é um medicamento.

Indicação: >= 19 anos.

Contra Indicação: Gestante/Lactantes/Crianças.

Contém: Gelatina e corantes.

\begin{tabular}{|l|c|c|}
\hline \multicolumn{1}{|c|}{ TABELA NUTRICIONAL } & QTD./DOSE & \%VD* \\
\hline TRIPTOFANO & $860 \mathrm{mg}$ & $100 \%$ \\
\hline
\end{tabular}

Não contém quantidades significativas de valor Energético, Carboidratos, Proteínas, Gorduras Totais, Gorduras Saturadas, Gorduras Trans, Fibra Alimentar e Sódio.

\subsection{Efeitos colaterais do triptofano}

O triptofano pode ter muitos benefícios para a saúde, mas o suplemento em excesso pode causar uma série de efeitos colaterais desagradáveis nas pessoas que incluem azia, dor de estômago, arroto, vômito e náusea, diarréia, perda de apetite, dores de cabeça, disfunção sexual, boca seca, sonolência, tontura, embaçamento visual, fraqueza muscular e fadiga.

\section{METODOLOGIA}

Este estudo trata-se de uma revisão bibliográfica realizada através das seguintes bases de dados: PubMed, Scielo e Google Acadêmico. Sendo utilizado os seguintes termos para realização da busca de dados em português: sistema nervoso central, depressão, aminoácidos, Triptofano e em inglês: Amino Acids, Tryptophan, Central Nervous System, Depression.

Bem como a busca do suplemento Triptolife através das informações passando pelo fabricante do mesmo: Life Natural.

\section{RESULTADOS E CONSIDERAÇÕES FINAIS}

No que refere à análise da composição do produto Triptolife, usando como referência os dados enviados pela empresa Life Natural, baseados em estudos recentes sobre sua composição, está de acordo com a necessidade para um bom funcionamento do organismo, a depender da necessidade de cada indivíduo e sua produção desta substância. Afirmo que a concordância se dá pelo relatório enviado pela empresa, não havendo 
necessidade de testagem já que sua fórmula foi aprovada pela Agência Brasileira de Vigilância Sanitária (ANVISA). Coube então a este estudo, comprovar a sua eficácia e não avaliar o produto e sua composição via testagem já que foi aprovado pelo órgão competente (ANVISA) e pela empresa Life Natural.

O produto Triptolife é um complemento que, como 5-HTP (5-hidroxitriptofano), atravessa facilmente a barreira hematoencefálica, o que não acontece com alguns alimentos que contêm triptofano, más que não atrasasse a barreira hematoencefálica tão facilmente.

A posologia aprovada em Portugal é de $300 \mathrm{mg}$ de 5-HTP por dia, o Triptolife apresenta 215 mg em cada cápsula, mediante ao consumo de alimentos com essa mesma substância, recomenda-se uma cápsula por dia já que alimentos podem suprir a diferença sem prejudicar o organismo.

O produto é natural não havendo necessidade de consumo sob prescrição médica, o que não significa que pode ser substituído por medicamentos por conta própria caso sejam apresentados sintomas derivados da desregulação desta substância. Todo e qualquer sintoma que prejudique o bem-estar de um indivíduo, caso não solucionado através de suplementos, deve ser procurado imediatamente um profissional da saúde.

O triptofano é fundamental em diversos mecanismos fisiológicos e comportamentais como sono, fadiga, ingestão alimentar, depressão entre outros. Na atividade física, importante para o bem-estar, há envolvimento do triptofano tanto em exercícios de longa como de curta duração.

Hoje vivemos do mal proveniente da utilização ineficaz da internet, como mídia social, facilitação de buscas de conteúdo, entretenimento desprovido de conhecimento útil, jogos, entre outros hábitos que causam disfunção em neurotransmissores como a dopamina, que por sua vez interfere na homeostase desequilibrando todo o sistema, prejudicando neurotransmissores como a serotonina. O triptofano torna-se útil nesses casos de sintomas provenientes dessa desregulação.

\section{REFERÊNCIAS}

COMAI, S. BERTAZZO, A. BRUGHERA, M. CROTTI, S. Tryptophan in health and disease. Advances in clinical chemistry v. 95, p. 165-218, 2020 https://doi.org/10.1016/bs.acc.2019.08.005 
STRASSER, B. GOSTNER, J. M. FUCHS, D. (2016). Mood, food, and cognition: role of tryptophan and serotonin. Current opinion in clinical nutrition and metabolic care, $v$. $19, \quad$ n. $\quad 1, \quad$ p. $\quad 55-61, \quad 2016$ https://doi.org/10.1097/MCO.0000000000000237

SONGTACHALERT, T., ROOMRUANGWONG, C., CARVALHO, A. F., BOURIN, M., \& MAES, M. Anxiety Disorders: Sex Differences in Serotonin and Tryptophan Metabolism. Current topics in medicinal chemistry v. 18, n.19, p. 17041715, 2018 https://doi.org/10.2174/1568026618666181115093136

GHEORGHE, C. E. MARTIN, J. A. MANRIQUEZ, F. V. DINAN, T. G. CRYAN, J. F. CLARKE, G. Focus on the essentials: tryptophan metabolism and the microbiome-gut-brain axis. Current opinion in pharmacology v.48, p.137-145, 2019 https://doi.org/10.1016/j.coph.2019.08.004

KALUZNA, C. J. GATAREK, P. CHIRUMBOLO, S., CHARTRAND, M. S. How important is tryptophan in human health?. Critical reviews in food science and nutrition v.59, n.1, p.72-88, 2019 https://doi.org/10.1080/10408398.2017.1357534 MARTINS, A. C. SILVA, C. TARLIANE, M. GLORIA, M. Determinação simultânea de precursores de serotonina - triptofano e 5-hidroxitriptofano - em café. Quím. Nova, São Paulo, v. 33, n. 2, p. 316-320, 2010 https://doi.org/10.1590/S0100$\underline{40422010000200016}$.

ALDRICH C. C. Central Nervous System-Related Pathogens. ACS infectious diseases, v. 5, n. 12, p.1975. https://doi.org/10.1021/acsinfecdis.9b00445

GULTYAEVA, V. V. ZINCHENKO, M. I. URYUMTSEV, D. Y., KRIVOSCHEKOV, S. G. AFTANAS, L. I. Exercise for depression treatment. Physiological mechanisms. MediasPhera v.119, n.7, p.112-119, 2019

LEE, C. H. GIULIANI, F. The Role of Inflammation in Depression and Fatigue. Fron$\begin{array}{lllllll}\text { tiers in immunology } & \text { v. } & 10, & \text { p. } & 1696, & 2019\end{array}$ https://doi.org/10.3389/fimmu.2019.01696

MALKIEWICZ, M. A. SZARMACH, A. SABISZ, A. CUBAŁA, W. J. SZUROWSKA, E. WINKLEWSKI, P. J. Blood-brain barrier permeability and physical exer$\begin{array}{lllllll}\text { cise. Journal of neuroinflammation } & \text { v. 16, n.1, } & \text { p. } & 15, & 2019\end{array}$ https://doi.org/10.1186/s12974-019-1403-X 